№. 4605 February 1, 1958

(ii) comparisons of labour efficiency as projected in the budget compared with past records.

A fall in profitability of capital employed could be due to a slowing down in turnover in capital. A breakdown of the elements of capital employed in relation to volumes of sales should give a lead as to where the slow-down is occurring. The fall in profit in total and in relation to capital employed may be due to a fall in turnover. If, however, the problem has remained intractable, and the shrinkage in turnover seems to be progressive over a long term, it must mean that there is either a developing shrinkage in the market for the company's products or that the company itself is becoming progressively uncompetitive.

If the problem is the former one, then the company must consider some more profitable use of capital.

If the problem seems to be one of competition, the compeny must discover whether the reason is pricewhich may be due to : inefficiency in direct cost; too high an overhead burden; an attempt to obtain too high a margin.

All these tests-and others-applied to the trend of an organization's figures in the final budget will indicate how a business is progressing in relation to its own standards. The question still remains whether it is improving its position in relation to its competitors and in relation to industry generally; whether it is better or less than average ; whether it is showing sound incipient strengths that could well be exploited. It is difficult to establish these facts unless there is some established method of comparison between firms. These take the form of detailed exchange of cost information on a common costing method or financial ratios.

The part the universities could play in management research was discussed by Prof. N. C. Hunt (University of Edinburgh), who suggested that many apparent personality problems in industry are, in fact, organizational problems. Given that organization, people would react similarly however well trained and well chosen they might be. They create situations in which workers who have been educated to be active, independent adults with real abilities are required to behave more and more like infants-dependent, subordinate and passive even though they may be well paid for it and well treated. This must tend to frustrations which in turn lead to an increase of aggression and $a$ reduction of efficiency. In this situation managers are asked to do the impossible. Whether they are autocratic or democratic, optimum results are persistently elusive.

Much could be gained by researchers going into businesses without a detailed frame of reference to investigate a particular problem. Free to follow their own devices thèy might well stumble upon important discoveries which might have been missed had a definite course been set. University researchers must keep themselves free to tackle problems in their own way, however 'practical' these problems may be. The business world would do well to make it possible for them to investigate problems which are not obviously practical and which may seem irrelevant.

Research in management must be a co-operative venture between the universities and the business community. It cannot be undertaken on any scale by business men immersed in the day-to-day problems of management. Neither can it be done by academics confined to laboratories and libraries.

Besides the sectional meetings, twenty-six discussion groups were arranged concerned with subjects varying from management ratios in the small firm to research in labour turnover; from research into industrial markets to ways in which management can be kept informed of scientific development and research findings. The groups led to extensive shaping of experience which should prove to be of considerable value to British industry.

The Conference was also addressed by Dr. A. King, deputy director of the European Productivity Agency, who illustrated the value of research as an investment.

T. H. HAWKINS

\title{
OBITUARIES
}

\section{Sir Ernest Kennaway, F.R.S.}

Throvar the death of Sir Ernest Kennaway, which took place on January 1 (peacefully in his sleep, at St. Bartholomew's Hospital), cancer research in Britain has lost its doyen, and experimental pathology one of its greatest figures.

Ernest Laurence Kennaway was born on May 23, 1881, the son of Laurence James Kennaway, of Exeter. As a scholar of New College, Oxford, he took a first-class in the final honours school of natural science in 1903. Proceeding to the Middlesex Hospital with a university scholarship, he graduated B.M., B.Ch., in 1907, and D.M. in 1911. After working for short periods at the Lister Institute and at University College, London, he then successively became demonstrator of physiology at St. Thomas's Hospital (1908), Hulme research student at Brasenose College, Oxford (1909), and demonstrator of physiology at Guy's Hospital (1909-14). In 1911, he was awarded a Radcliffe travelling fellowship by the University of Oxford, and studied at Heidelberg and at Munich. In 1915, he obtained the D.Sc. of the University of London.

He joined the staff of the Cancer Hospital in London as physiological chemist in 1921, and in due course became director of its Research Institute (now the Chester Beatty Research Institute), in succession to Dr. Archibald Leitch ; and was also elected professor of experimental pathology in the University of London. He retired from the staff of the Royal Cancer Hospital in 1946, becoming professor emeritus, and continued his researches at St. Bartholomew's Hospital. In a long life he accumulated many honours-the William Julius Mickle fellowship of the University of London, the first award of the Anna Fuller Memorial Prize (jointly), the Garton Prize of the British Empire Cancer Campaign, the Walker Prize of the Royal College of Surgeons of England, the Baly Medal of the Royal College of Physicians of London, the Osler Memorial Medal of the University of Oxford, and an honorary fellowship of New College -among others. He was elected Fellow of the Royal Society in 1934 (and a Royal Medallist in 1941), 
and of the Royal College of Physicians in 1937, and received the honour of knighthood in 1947.

In the period from about 1910 to 1920 , Kennaway was the author of a whole series of papers, on a great diversity of topics, which unmistakably revealed the breadth of his knowledge and interests in chemistry, physiology and pathology, and gave a taste of things to come. Certainly, however, it is upon his massive achievements in the sphere of malignant disease that his name and fame are based and will endure. In the early 'twenties, great efforts were under way to elucidate the nature of the cancer-producing agent in tar and pitch, following the successful induction of cancer through application of coal-tar to the rabbit skin by Yamagiwa and Ichikawa (1915), and in the mouse by Tsutsui (1918). Between 1921 and 1926, Bloch in Zurich had found that the active substance was concentrated in the higher boiling fractions as a neutral compound probably belonging to the class of cyclic hydrocarbons. In 1924-25, Kennaway succeeded in producing carcinogenic tars by the pyrolysis of many organic materials, and by leading acetylene and isoprene with hydrogen through heated tubes. The tars obtained at successively higher temperatures showed an ascending potency, and the results could be explained by assuming that acetylene was a common decomposition product, and that the carcinogenic material was built up from it. In all this work, Kennaway ever acknowledged the value of Berthelot's classical paper of 1866, describing for the first time the production from acetylene of these very kinds of molecule.

We are fortunate, indeed, that he left his own characteristic account of these and later developments (Brit. Med. J., 2, 749; 1955), setting forth their history, and making clear the essential part played by others at the Cancer Hospital-W. V. Mayneord's examination of the fluorescence spectra of the carcinogenic tars, and the discovery of their special qualities (1927); the development of this clue by I. Hieger ; the discovery that $1: 2$-benzanthracene gave a spectrum similar to that of the carcinogenic mixtures ; and J. W. Cook's studies of the benzanthracene homologues. About this time, Clar had just published methods for the synthesis of certain benzan. thracene hydrocarbons. These compounds were tested by Kennaway and Hieger (1929-30), who soon observed positive results with $1: 2: 5: 6$-dibenzanthracene : this was the first pure compound manifesting pronounced carcinogenic properties, and one cannot forget the satisfaction and modest pride which Kennaway obtained from the fact. The fluorescence spectrum-in Kennaway's words "the single thread that led all through this labyrinth"-was also used in the concentration of the agent from coal-tar pitch, culminating in the isolation of a hydrocarbon which showed the characteristic spectrum and which proved to be highly carcinogenic. Its properties suggested one of the two benzpyrenes, and these were synthesized by J. W. Cook and C. L. Hewett, who were then able to prove the identity of one of the compounds (3:4-benzpyrene), and the substance from pitch. All these, and many other results which Kennaway alone inspired, are embodied in numerous papers (many of them classics) in the scientific literature at home and abroad, and, most notably, in a celebrated series which appeared in the Proceedings of the Royal Society during 1932-42. What undoubtedly emerged. from almost thirty years of brilliant work was a satisfying and indeed beautiful correlation between chemical constitution and biological action, whereby the carcinogenic sub-classes of polynuclear hydrocarbons could clearly be related to the parent substance phenanthrene, in a system suggesting dependence upon certain optimal features of molecular size, shape, substitution and resctivity. But we must not minimize another result-namely, the profound practical influence which was exerted upon the whole of cancer research, and indeed biology at large, from the mere availability of these potent carcinogens, so rendering possible, and catalysing, numerous other investigations, and additions to knowledge, which could not have been attained without them.

No imagination is needed to see how this career demanded a patient sense of purpose over so many years. In certain ways Kennaway possessed a unique combination of qualities - in his intellectual aptitudes, his chemical sympathy and knowledge, and in his unrivalled skill in applying them to physiology and pathology. Apart from his modern scientific bent, he was also a true naturalist, believing greatly in field work and epidemiology. His standards of scientific evidence were rigorous and severe, to the point of austerity. His experimental methods were simple, practical and decisive, and a delight to watch in execution. He was much less interested in hypotheses and explanations, and although his own work had lain almost entirely in the chemistry of carcinogenesis, he remained completely open and free to accept any other mechanism or interpretation-provided only that the facts were ascertained, and not an instant before. Added to all these gifts, he was a master of scientific expression, and of English construction.

We have lost a great discoverer and scientific worthy. Among his personal attributes two things prevailed. First, his profound agnosticism. Secondly, a superb fortitude, which enabled him to triumph over disability, illness and accident, and to continue his researches long after his official retirement and almost to the day of his death. Of course, he had many other interests, and many human concerns which he did not parade and which, contrariwise, he often tried to conceal. It is idle to pretend that Kennaway was easy, or that he could readily apply to ordinary judgments the quality of detachment he brought to his special field. But for how many can anything of the kind be claimed ? Although he could be subjective and quixotic even more than most of us, these foibles were mere additions-often endearingto the fascination of an already complex human character, and had no real bearing on the solid worth of his permanent achievement.

No appreciation could be complete which failed to refer to a factor at all times apparent to those who worked with him-the part played by Lady Kennaway in every aspect of his life and contribution. Not in any small measure due to his helpmeet, he wrote a vast chapter in cancer research and chemical pathology, which nothing can diminish, or take away.

\section{A. HaDDow}

\section{Dr. A. J. Ewins, F.R.S.}

Dr. Arthur James Ewins died after a long illness on December 24, aged seventy-five. He will long be remembered for his discovery of several important chemotherapeutic remedies.

Ewins was born in 1882 at Norwood, the son of Joseph Ewins, who was a signalman on the London and South-Eastern Railway. A scholarship took him to Alleyn's School, Dulwich. Leaving at the age of 